\title{
RESPIRATORY FUNCTION FOLLOWING PULMONARY INFARCTS
}

\author{
BY \\ OVE JACOBY, TYGE SØNDERGAARD, AND H. H. WANDALL \\ From the Copenhagen City Hospital and the Oresund Chest Hospital
}

(RECEIVED FOR PUBLICATION DECEMBER 24, 1954)

Some years ago one of our patients, a man aged 40 , had a standard gastric resection for duodenal ulcer and subsequently attacks of severe pulmonary embolism. The $x$-ray finding was that of infarction involving the greater part of the right lung as well as smaller sections of the left. The patient recovered, and according to the $x$-ray films the affected lung cleared almost entirely.

The post-operative fate of this patient posed the question of whether the radiological clearing was paralleled by a return of respiratory function. As bronchospirometry suggested a discrepancy between the radiological recovery and return of lung function, some patients were studied in an endeavour to elucidate this problem.

\section{Material}

For follow-up studies we selected five patients complaining of residual dyspnoea following episodes with clinical signs of infarction, viz., sudden chest pain and cough productive of blood-stained sputum and $x$-ray abnormalities which cleared later. Quite marked dyspnoea was a characteristic feature in four instances (Cases 1, 2, 3, 4), while Case 5 had only slight dyspnoea on exertion. In two cases normal chest radiographs before the operation were available, whereas three patients were emergency admissions.

Radiologically the findings following the onset of the infarction disclosed that the lesion involved the greater part of the right lung in one (Case 2), the entire right lower lobe in two (Cases 1 and 4), the axillary subapical segment in one (Case 3 ), and both lower lobes in one (Case 5). The last-mentioned patient showed some pleural effusion as well.

In three instances the pulmonary lesion was related to already existing thrombotic disease in the lower extremities (Cases 3, 4, and 5), while in two patients (Cases 1 and 2) the pulmonary episode occurred without warning. In Case 1 a transitory atelectasis, spreading plate-like in the right lower lobe, developed immediately after operation. The atelectasis had cleared completely on radiographs a week before the onset of infarction.

Two patients (Cases 2 and 3) had had abdominal operations and another two (Cases 4 and 5) severe

TABLE I

CLINICAL FINDINGS IN FIVE CASES

\begin{tabular}{|c|c|c|c|}
\hline & $\begin{array}{l}\text { Hospital No., } \\
\text { Sex, Age }\end{array}$ & Diagnosis & Operation \\
\hline Case 1 & $\begin{array}{l}2511 / 47 \\
\text { Male,58 }\end{array}$ & Oesophageal cyst & Left-sided thoraco- \\
\hline Case 2 & $\begin{array}{l}775 / 51 \\
\text { Male, } 40\end{array}$ & Duodenal ulcer & $\begin{array}{l}\text { Gotomy } \\
\text { Gastric resection } \\
\text { (Polya) }\end{array}$ \\
\hline Case 3 & $\begin{array}{l}1208 / 51 \\
\text { Female, } 40\end{array}$ & Appendicitis & Laparotomy with \\
\hline Case 4 & $\begin{array}{l}1516 / 51 \\
\text { Male, } 31\end{array}$ & $\begin{array}{l}\text { Dilaceration of right } \\
\text { leg; open fracture of }\end{array}$ & $\begin{array}{l}\text { Revision of the } \\
\text { wounds }\end{array}$ \\
\hline Case 5 & $\begin{array}{l}2885 / 51 \\
\text { Male, } 37\end{array}$ & $\begin{array}{l}\text { Fracture of the } \\
\text { lateral condyle of } \\
\text { the left tibia }\end{array}$ & , \\
\hline
\end{tabular}

TABLE II

THROMBO-EMBOLISM IN FIVE CASES

\begin{tabular}{|c|c|c|c|c|}
\hline & \multicolumn{3}{|c|}{ Pulmonary Embolism } & \multirow[b]{2}{*}{$\begin{array}{l}\text { Follow-up } \\
\text { Period }\end{array}$} \\
\hline & $\begin{array}{l}\text { Time of Onset } \\
\text { after Operation }\end{array}$ & $\begin{array}{l}\text { Site and } \\
\text { Extent }\end{array}$ & Duration & \\
\hline Case 1 & 18 days & $\begin{array}{l}\text { Right lower } \\
\text { lobe }\end{array}$ & Unknown & $3 \frac{3}{4}$ years \\
\hline Case 2 & $\begin{array}{l}3 \text { days with } \\
\text { steady pro- } \\
\text { gression un- } \\
\text { til the 29th } \\
\text { day, then } \\
\text { massive } \\
\text { embolism }\end{array}$ & $\begin{array}{l}\text { First L. lower } \\
\text { lobe,then R. } \\
\text { lower lobe. } \\
\text { Eventually } \\
\text { almost the } \\
\text { entire R. } \\
\text { lung }\end{array}$ & $\begin{array}{l}4 \text { weeks after } \\
\text { the onset of } \\
\text { massive } \\
\text { embolism }\end{array}$ & $\begin{array}{l}\text { (1) } 4 \text { mth. } \\
\text { after first } \\
\text { attack, } 2 \\
\text { mth. after } \\
\text { radiological } \\
\text { clearing. } \\
\text { (2) } 2 \text { years } \\
\text { after }\end{array}$ \\
\hline Case 3 & 7 days & $\begin{array}{l}\text { R. upper } \\
\text { lobe, axil- } \\
\text { lary sub- } \\
\text { apical } \\
\text { segment }\end{array}$ & $\begin{array}{l}\text { About } 6 \\
\text { weeks before } \\
\text { the lesion } \\
\text { subsided }\end{array}$ & $\begin{array}{l}\text { operation } \\
3 \text { mth. }\end{array}$ \\
\hline Case 4 & 19 days & R. lower lobe & $\begin{array}{l}\text { Complete } \\
\text { subsidence } \\
\text { within } 8 \\
\text { weeks }\end{array}$ & $3 \frac{1}{2} \mathrm{mth}$. \\
\hline Case 5 & 28 days & $\begin{array}{l}\text { Both lower } \\
\text { lobes }\end{array}$ & $\begin{array}{l}\text { Clearing } 3 \\
\text { weeks later }\end{array}$ & $3 \mathrm{mth}$. \\
\hline
\end{tabular}


TABLE III

THE BRONCHOSPIROMETRIC RESULTS

\begin{tabular}{|c|c|c|c|c|c|c|c|c|c|c|c|c|c|c|c|c|}
\hline \multirow{2}{*}{$\begin{array}{c}\text { Case and } \\
\text { Hospital Nos. }\end{array}$} & \multicolumn{4}{|c|}{ T.V. } & \multicolumn{3}{|c|}{ M.V. } & \multicolumn{2}{|c|}{ V.C. } & \multicolumn{2}{|c|}{ M.B.C. } & \multicolumn{2}{|c|}{$\mathrm{O}^{2}$-opt. } & \multirow{2}{*}{$\frac{\text { M.B.C. }- \text { M.V. }}{\text { M.V. } \%}=$ V.R. } & \multirow{2}{*}{$\frac{\mathrm{O}^{20} \%}{\mathrm{M.V} . \%}=\mathrm{E} . \mathrm{Q}$. } & \multirow{2}{*}{ B.H $\frac{\frac{\bar{\sigma}}{\frac{\sigma}{\sigma}}}{\text {. }}$} \\
\hline & & nl. & $\%$ & Freq. & $\mathrm{ml}$. & $\%$ & Freq. & $\mathrm{ml}$. & $\%$ & $\mathrm{ml}$. & $\%$ & $\mathrm{ml}$ & $\%$ & & & \\
\hline \multirow{2}{*}{$\begin{array}{l}\text { Case } 1 \\
2511 / 47\end{array}$} & $\mathbf{R}$ & 500 & 50 & 16 & 8,000 & 50 & 20 & 1,000 & 56 & 2,000 & 55 & 150 & 35 & 150 & 07 & \\
\hline & & 500 & 50 & 16 & 8,000 & 50 & 20 & 800 & 44 & 16,000 & 45 & 275 & 65 & 100 & $1 \cdot 3$ & \\
\hline \multirow{4}{*}{$\begin{array}{l}\text { Case } 2 \\
775 / 51 \quad \text { 1st test }\end{array}$} & $\mathbf{R}$ & 500 & 56 & 16 & 8,000 & 56 & 18 & 800 & & 14,400 & & 100 & 21 & 44 & 0.37 & \\
\hline & & 400 & 44 & 16 & 6,400 & 44 & & & & & & 370 & 79 & & 1.8 & \\
\hline & & 400 & 50 & 14 & 5,600 & 46 & 13 & 1,000 & 56 & 13,000 & 51 & 140 & 50 & 130 & 1.09 & \\
\hline & & 400 & 50 & 16 & 6,400 & 54 & 16 & 800 & 44 & 12,800 & 49 & 140 & 50 & 100 & 0.93 & \\
\hline \multirow{2}{*}{$\begin{array}{l}\text { Case } 3 \\
1204 / 51\end{array}$} & & 150 & 38 & 35 & 5,300 & 41 & 22 & 350 & 26 & 7,700 & 27 & 150 & 43 & 45 & 1.05 & \\
\hline & & 250 & 62 & 31 & 7,600 & 59 & 21 & 1,000 & 74 & 21,000 & 73 & 200 & 57 & 57 & 0.97 & \\
\hline \multirow{2}{*}{$\begin{array}{l}\text { Case } 4 \\
1516 / 51\end{array}$} & & 400 & 37 & 17 & 6,800 & 41 & 26 & 800 & 42 & 20,800 & 44 & 230 & 35 & 200 & 0.85 & \\
\hline & & 700 & 63 & 17 & 10,000 & 59 & 24 & 1,100 & 58 & 26,400 & 56 & 420 & 65 & 160 & $1 \cdot 1$ & \\
\hline \multirow[t]{2}{*}{$\begin{array}{l}\text { Case } 5 \\
2885 / 51\end{array}$} & & 350 & 54 & 21 & 7,350 & 51 & 30 & 500 & 36 & 15,000 & 70 & 150 & 50 & 100 & 1 & 35 \\
\hline & & 300 & 46 & 23 & 6,900 & 49 & 7 & 900 & 64 & 6,300 & 30 & 150 & 50 & 0 & 1 & 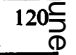 \\
\hline
\end{tabular}

T.V. =tidal volume. M.V. = minute volume. V.C. $=$ vital vapacity. M.B.C. $=$ maximum breathing capacity. $\mathrm{O}^{2}-$ opt. $=$ oxygen consumptiono V.R. $=$ ventilatory reserve $=\frac{\text { M.B.C. }- \text { M.V. }}{\text { M.V. } \%}$ E.Q. $=$ equivalent of ventilation. B.H. $=$ breath holding.

injuries of the extremities and were lying supine in bed, immobilized by some apparatus for traction.

The follow-up period ranged from three months to three years.

Case 2 has subsequently had a supradiaphragmatic vagus resection for peptic jejunal ulcer with a quick and uneventful post-operative course. While the left chest was open, the surgeon examined the left lung carefully without being able to demonstrate any vestige of infarctions previously observed on the $x$-ray films.

Case 3 late $i$ had a cholecystectomy; the operation was uncomplicated, but the post-operative course was rather stormy with some respiratory distress.

The bronchospirometric findings (Table III) were as follows:-

In the three cases in which the right lung or lower

- lobe was involved, the ventilation was good, whereas the oxygen consumption was more or less reduced. This impairment was relatively most marked in the first patient, who was re-examined three and threequarter years after the operation. The findings in Case 2 are also interesting. The marked difference between the function on the right and left side apparent at the first recording had disappeared at the re-examination, in which the only abnormality was relatively low values (the patient's height is $176 \mathrm{~cm}$. and his weight $88.6 \mathrm{~kg}$.). The incompleteness of the first recording, however, greatly reduces the value of this finding.

In Case 3 (infarct in the right upper lobe) the ventilation was impaired, while the reduction in oxygen consumption was slight. Case 5 is a typicat example of left-sided ventilatory impairment.

Twenty-three months after the onset of infarction - in Case 2 an angiocardiopulmograph* was performe 4 to elucidate the state of the pulmonary circulation $\overrightarrow{\overrightarrow{0}}$ This procedure showed normal passage throug $\mathrm{P}$ the heart as well as normal filling and calibre of the left pulmonary artery and its branches. The right pulmonary artery, on the other hand, was unmistakably narrowed compared with the left, and its filling was poor and irregular. Its periphera* branches were dilated and of an irregular an\& tortuous course. There was a definite delay in the passage of the opaque medium through the vessele of the right lung as against the left.

\section{Discussion}

These investigations show that, even though the clinical and radiological disease caused by pufo monary infarction disappears almost entirely nothing can be predicted about the function of the lung. It may return, but does not necessarily do so Oxygen consumption was reduced in three of the five patients. Ventilation was also reduced where pleural effusion had been present and when th\& interval between the onset of infarction and re-examination was short.

As the reliability of the method of examination as well as its sources of error have previously beep

* By the kind permission of Professor P. Flemming Møller the angio cardiopulmography was performed by Dr. Gregers Thomsen in the Radiological Department of the University Hospital, Copenhagep We are greatly indebted for their interest and assistance. 
discussed by one of us (Jacoby, 1951), only a few comments will be made here. It must be borne in mind that the readings can only be considered representative of an entire lung and its function. A reduction in the function of minor segments of one lung may not be revealed, if the decrease in function is compensated for by adjoining segments. (This could explain the findings in Case 3 , only a small segment of the right lung being involved and no alterations in the oxygen uptake of that lung being demonstrable.) Bilateral lesions equalling each other in extent and severity may lead to uniform impairment in function of the two lungs, resulting in the measurement of equally low values but within the range of normal (cf. the findings in Case 5).

The discrepancy between ventilation and oxygen consumption demands a further consideration of the two components involved in the formation of infarcts, viz., the occlusion of the pulmonary artery and the parenchymal damage.

We shall not discuss in detail whether the arterial occlusion is due to embolism or to thrombosis or whether destruction of the alveolar walls must be demanded before the lesion is accepted as an actual infarct. As mentioned above, however, the pulmonary infarct developed in two cases (1 and 2) without the known existence of a thrombotic process elsewhere. In Case 1 the re-aerated right lower lobe became the site of the haemorrhagic infarct, suggesting a local thrombosis within the lobar branch of the pulmonary artery as the causal factor. It is also worth noting that the most striking reduction in oxygen consumption was found in this patient, although almost four years had passed between admission to hospital and re-examination. Unfortunately angiocardiopulmography, so valuable for the interpretation of the findings in this case, is not of therapeutic, but merely of investigational, interest.

When, as in some of our cases, a lung or a lobe has been involved in a process of complete consolidation and has soon returned to normal radiologically, profound destruction is unlikely. Therefore, the type of lesion under discussion is probably to be classified according to Hampton and Castleman as "incomplete infarction."

The constituents necessary for the development of the parenchymal lesion are still under discussion.

The classical view that occlusion of a branch of the pulmonary artery can be followed by infarction only in the presence of congestion in the pulmonary circulation seems to be losing ground. The scepticism is due not least to the common postoperative occurrence of these phenomena in other- wise healthy individuals (Maier, 1949; Hampton and Castleman, 1940).

Recently, the blood supply through the bronchial arteries has been considered as a factor of major importance for the development of the haemorrhagic zones (Ellis, Grindlay, and Edwards, 1952; Shedd, Alley, and Lindskog, 1951). When a branch of the pulmonary artery becomes occluded the bronchial arterial system empties blood through precapillary anastomoses into the pulmonary arterial system, and the area distal to the embolus is transformed into a "diverticulum" on the bronchial artery. In this way a "high pressure system" empties into a "low pressure area" in which the conditions of circulation are already pathologically changed. This constitutes the soil for the gradual congestion and haemorrhage within the occluded area as the bronchial arteries dilate. As early as the nineteenth century Virchow called attention to the existence of dilatation of these arteries in cases of pulmonary embolism and infarction.

As regards the fate of the haemorrhagic area, incomplete infarcts will heal by resolution, leaving the structure of the parenchyma intact, whereas " actual infarcts" with necrosis will heal by organization, thus turning into fibrous areas. In the vicinity one may find the completely occluded branch of the pulmonary artery to the area involved (Hampton and Castleman).

The occluding process within the pulmonary arterial branches can be located by angiocardiopulmography. It is a very useful method for any attempt at correlating radiographic and functional findings on a patho-anatomical background. Unfortunately, the conditions in question make the application of this procedure advisable or justifiable in only a few cases. Furthermore, repeated angiographic examinations are necessary in each case to determine the extent of the occlusion and the degree of recanalization that takes place later on.

Experimental investigations (Lochhead, Roberts, and Dotter, 1952) have demonstrated the angiocardiopulmographic pattern in the acute phase of pulmonary arterial embolism. In relation to the problems under discussion the demonstration of the contrast medium often passing beyond the occluding embolus is of interest in so far as it underlines the fact that an embolus need not stop the arterial blood flow completely. The local alterations in pressure taking place behind the embolus seem to be the only trigger mechanism necessary for increasing the blood supply through the bronchial arteries. 
Studies on the late effects of embolism do not appear to have been reported in the accessible literature.

The angiocardiopulmographic findings in Case 2 were, as mentioned above, irregular outlines of the pulmonary artery with highly tortuous and slightly dilated peripheral arteries within the previously consolidated area. Evidently, complete recanalization had taken place. The delay in blood flow found in this case leaves open for discussion to what extent the pulmonary arterial system has been deprived of its function. The changes in calibre and pattern of the vessels in the diseased area may be explained by the existence of an increase in pressure originating in the establishment of a collateral circulation. Marchand, Gilroy, and Wilson (1950) as well as Cockett and Vass (1951) have shown that a very powerful collateral circulation may develop from the bronchial arteries under widely different conditions. As to function, the bronchospirometric values at the time of the angiographic examination did not show any impairment in respiratory function.

- This means that the localized pathological circulation has no influence on the function of the lung as a whole, but it does not rule out the possibility of severe dysfunction of one or more segments. It must not be forgotten that (as stressed by Churchill in 1949) our physiological methods for registering pulmonary function do not give any information about segmental function. Consequently, no conclusive interpretation of the findings in our case is possible.

According to what has been stated above, an area of consolidation regains most of its ventilatory capacity apart from the alterations caused by small scarring patches, but the pulmonary circulation in that area is probably more or less impaired; it probably remains shunted to the systemic circulation.

The functional significance of this phenomenon has been elucidated by the studies of Bloomer, Harrison, Lindskog, and Liebow (1949). Following ligation of a lobar artery, they observed respiratory function of the lobe and a flow through the bronchial artery so marked that the minute output of the left ventricle was increased by one-third of that of the right. These findings accord well with the reported observations. Reduced oxygen consumption in normally ventilated areas of the lung may be adequately explained merely by the flow of oxygenated arterial blood through that area, subsiding as recanalization of the pulmonary arterial branch takes place. The striking dyspnoea in foup of our five patients finds perhaps a better explanation in the increased strain on the left heart caused by을 a free drainage of the bronchial blood flow intos the lesser circulation.

The present orientating investigations into the pulmonary function following pulmonary embolism have revealed some facts of interest for the evalua? tion of the patients' complaints and for the under $\overrightarrow{\vec{\omega}}$ standing of variations in the adaptation of the pulmonary circulation.

It remains to be shown by further studies to what extent and under which conditions the pulmonary function can improve, how soon it can be restored and whether the variations are correlated to the methods of treatment (rapidly acting anticoagulantso etc.). In judging the patients' working capacity it must be borne in mind that disappearance of $x$-rase changes is not tantamount to a restored pulmonar function. A persistent dyspnoea may be explained by the secondary strain on the heart.

From a theoretical point of view the findings calf for experiments to elucidate to what extent the cardio-respiratory function is influenced by shifts in the balance between the blood flow through the pulmonary and bronchial arteries. It must be realized that, once developed, the anastomoses between the pulmonary and bronchial arteria 5 system may influence the capacity as well as flow of blood through the pulmonary vascular bed.

\section{SUMMARY}

Bronchospirometric measurements were carried out at varying periods of time after fairly large pulmonary infarcts in five patients. In addition, one of these patients was examined by angiocardio pulmography. The observations show that, witl disappearance of consolidation on the $x$-ray film the ventilation capacity is normal, while the oxygen uptake need not reach normal values.

\section{REFERENCES}

Bloomer, W. E., Harrison, W., Lindskog, G. E., and Liebow, A. A (1949). Amer. J. Physiol., 157, 317.

Churchill, E. D. (1949). J. thorac. Surg., 18, 279.

Cockett, F. B., and Vass, C. C. N. (1951). Thorax, 6, 268. Cockett, F. B., and Vass, C. C. N. (1951). Thorax, 6, 268.
Ellis, F., Grindlay, J. H., and Edwards, J. E. (1952). Surgerv, 31, 1670 U
Hampton, A. O., and Castleman, B. (1940). Amer. J. Roentgenol. ampton, $A$.

Jacoby, O. (1951). Ugeskr. Logg., 113, 1365. Jacoby, O. (1951), Ugeskr. Logg., 113, 1365.
Lochhead, Roger P., Roberts, D. J., and Dotter, C. T. (1952). Amer
J. Roentgenol., 68, 627.

Maier, H. C. (1949). Ann. Surg., 130, 790.

Marchand, Paul, Gilroy, J. C., and Wilson, V. H. (1950). Thorax, $\mathbf{5}_{\text {, }}$ 207.

Shedd, D. P $22,537$. 